Research Article

\title{
Design of a Patch Antenna on Different Substrates for Higher Fre- quencies Applications
}

\author{
Gulzar Ahmad*, Muhammad Bilal Khan, Junaid Bahadar Khan and Faheem Ali
}

Department of Electrical Engineering, UET Peshawar, Khyber Pakhtunkhwa, Pakistan.

\begin{abstract}
The microstrip patch antennas offered in this research exposure was designed and simulated on three different substrate materials to investigate its performance for its employment in future higher frequencies wireless applications in general and $5 \mathrm{G}$ cellular applications in particular. In the past, researchers employed different dielectric substrates to analyze microstrip patch antenna in low frequency range. In the presented research work three different dielectric materials were investigated in the higher frequency range starting from $12 \mathrm{GHz}$ as the scientists consider these higher frequencies suitable for future wireless mobile applications. Three simple rectangular patch structures were designed on three different insulated substrates including FR-4, Mica and Preperm. The thickness of the Mica was $2.15 \mathrm{~mm}$ and the thickness of FR-4 was $2 \mathrm{~mm}$, while the thickness of the Preperm was reduced to $1.75 \mathrm{~mm}$. The parameters of all the three antennas were optimized to demonstrate better results. The results obtained from all the aforementioned structures were compared with one another. Emphasis was made on the bandwidth expansion and improvement on the efficiency. The Patch antenna on Mica substrate demonstrated better results as compared to the antennas on Preperm and FR-4 substrates. Patch antenna on Mica substrate attained huge dual bandwidths of $26.06 \mathrm{GHz}$ and $16.16 \mathrm{GHz}$ respectively. It attained greater efficiency of $81.88 \%$ and a maximum gain of $8.19 \mathrm{dBi}$. Based on the results attained by the antenna on the Mica substrate, it is established that it will be the best antenna for wireless mobile applications at higher frequencies as compared to the remaining two antennas.

Received: January 13, 2020; Accepted: May 23, 2020; Published: June 30, 2020

*Correspondence: Gulzar Ahmad, Department of Electrical Engineering, UET Peshawar, Khyber Pakhtunkhwa, Pakistan; Email: gulzar@ uetpeshawar.edu.pk

Citation: Ahmad, G., M.B. Khan, J.B. Khan and F. Ali. 2020. Design of a patch antenna on different substrates for higher frequencies applications. Journal of Engineering and Applied Sciences, 39(1): 94-102.

DOI: http://dx.doi.org/10.17582/journal.jeas/39.1.94.102

Keywords: Return loss, Bandwidth, Efficiency, Microstrip patch antenna, Future wireless applications
\end{abstract}

\section{Introduction}

$\mathrm{M}$ icrostrip patch antenna is a charming area for the scientists doing research on the future wireless mobile phones. The antenna for future wireless mobile appliances must encompass a straightforward clear structure that will result in its inexpensive production. The use of higher frequencies for future wireless mobile phones had minimized the volume of these antennas. The scientists are emphasizing on high frequencies band from $12 \mathrm{GHz}$ to $80 \mathrm{GHz}$. During the designing process the selection of an appropriate substrate's material plays an important role. The appropriate substrate material not only provides mechanical strength but its electrical characteristics are very important for the size, resonant frequency and the improvement of the antenna's efficiency. This is why the substrate material must fulfill the electrical and mechanical prerequisites of the antenna. The author of (Nor et al., 2016) presented an antenna that demonstrated a small bandwidth of $2.1 \mathrm{GHz}$ but the Gain of this antenna was very large as compared to the 
proposed antennas of this article. The substrate of the design presented in (Ahmad et al., 2018) was made from Preperm L-450 and the bandwidth attained by this antenna was $5.45 \mathrm{GHz}$ with the return loss of $62.38 \mathrm{~dB}$ at the center frequency of $16.93 \mathrm{GHz}$. Preperm of $1.64 \mathrm{~mm}$ thickness was engaged to achieve the bandwidth of $13.13 \mathrm{GHz}$ (Ahmad and Babar, 2019). A gain of $7 \mathrm{dBi}$ and efficiency of 0.99 were demonstrated by this patch antenna. The researchers in (Ahmad et al., 2018) presented an antenna having a bandwidth of $5.51 \mathrm{GHz}$. The author in (Khan and Rajeesh, 2012) presented five patch antennas on five different substrates for applications in X-band. The performances of all these antennas have been critically analyzed. In light of results comparison, RT Duroid was declared as a good dielectric substrate for the microstrip patch antenna in X-band applications. The results of patch antennas which were designed on various substrate materials were compared in (Amba and Nandita, 2017). Roger RO4003(tm) was declared the best material based on the antenna's efficiency as it attained 92\% efficiency. In (Israa and Riydah, 2018) the increase in the relative permittivity of dielectric material resulted in decrease in the bandwidth, directivity and VSWR. On other hand this increase resulted in the improvement of the specific absorption rate (SAR) of the antenna.

It was concluded in (Mohamed, 2017) that the selection of high dielectric constant substrate reduces the size as well as the efficiency. This means that this kind of material can be selected for the size miniaturization of the patch antenna on the expense of efficiency. This small sized antenna will not be efficient. A thick substrate material having low value of relative permittivity attains high efficiency, a wide bandwidth but the size of the antenna will be large (Gurpreet and Sonia, 2016). The future wireless antennas need to have a large bandwidth and high efficiency to cope with the demands of the end users. In this article a simple patch has been designed using three different substrate materials to investigate its performance at higher frequency bands. The substrate giving better results in terms of bandwidth, efficiency and gain will be recommended for future mobile applications. Microstrip line feeding was employed in the proposed antenna as it can be made-up without difficulty.

\section{Antenna design}

Three antennas on different substrate materials were designed and analyzed analytically. Design parameters of all these three antennas on different substrate materials have been explained in the subsequent sections. All these three antennas have very simple rectangular structures enabling the manufacturer to fabricate it easily and economically. The thickness of the substrate material of the Preperm antenna was $1.75 \mathrm{~mm}$ while the thicknesses of the remaining two substrates were increased from $1.75 \mathrm{~mm}$ to $2 \mathrm{~mm}$ and $2.15 \mathrm{~mm}$ for attaining desirable results. The permittivity and thickness of all the three different substrate are exposed in Table 1.

Table 1: Specifications of all the three substrate's materials.

\section{S. No Substrate's material Thickness Relative permittivity}

$\begin{array}{llll}1 & \text { Preperm L680HF } & 1.75 \mathrm{~mm} & 6.8 \\ 2 & \text { Mica } & 2.15 \mathrm{~mm} & 6 \\ 3 & \text { FR-4 } & 2.00 \mathrm{~mm} & 4.3\end{array}$

\section{Preperm substrate}

The thickness of the Preperm material was $1.75 \mathrm{~mm}$ and its relative permittivity was 6.8 . The side view, patch view and ground view are exposed in Figures 1, 2 and 3, respectively. The surface area of the Preperm substrate was $7.99 \times 5.16 \mathrm{~mm}^{2}$, while the surface area of the copper patch was $4.59 \times 2.73 \mathrm{~mm}^{2}$. The thickness of the copper patch as well as copper ground was $0.1 \mathrm{~mm}$.

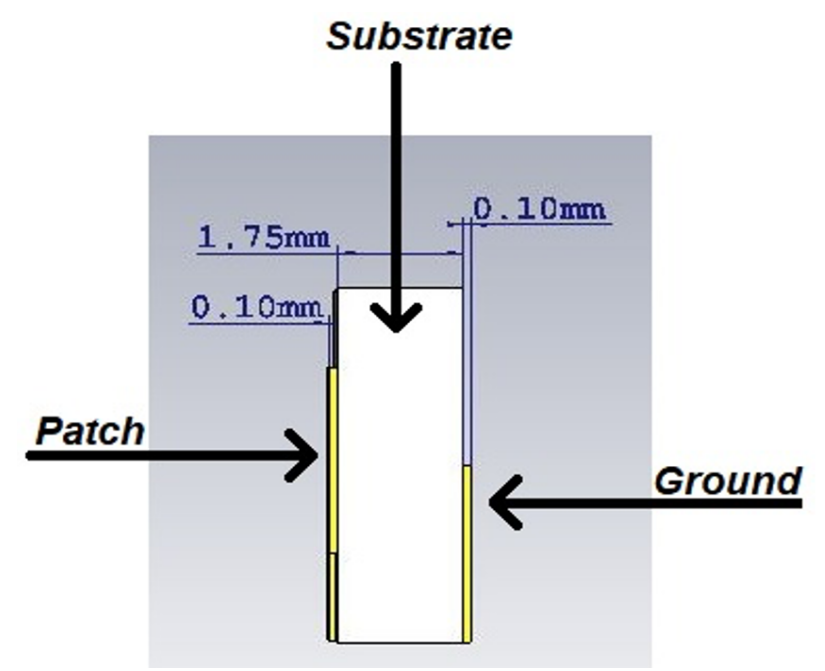

Figure 1: Side view of Preperm antenna.

The transmission feed line was engaged to energize the structure and its surface area was $1.29 \times 0.8 \mathrm{~mm}^{2}$ as depicted in Figure 2.

As evident from Figure 3 the copper ground was reduced by $50 \%$ and its surface area was made equal to $7.99 \times 2.58 \mathrm{~mm}^{2}$. 


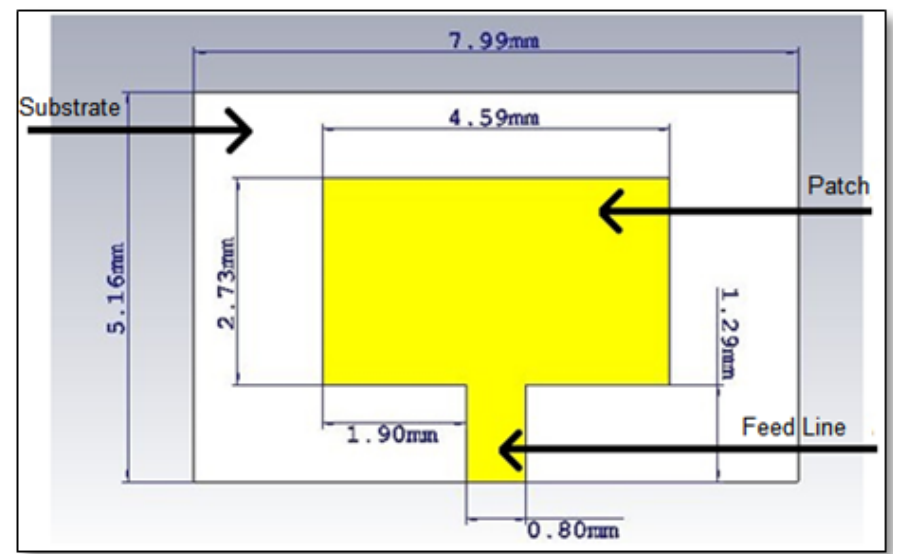

Figure 2: Patch View of the Preperm antenna.

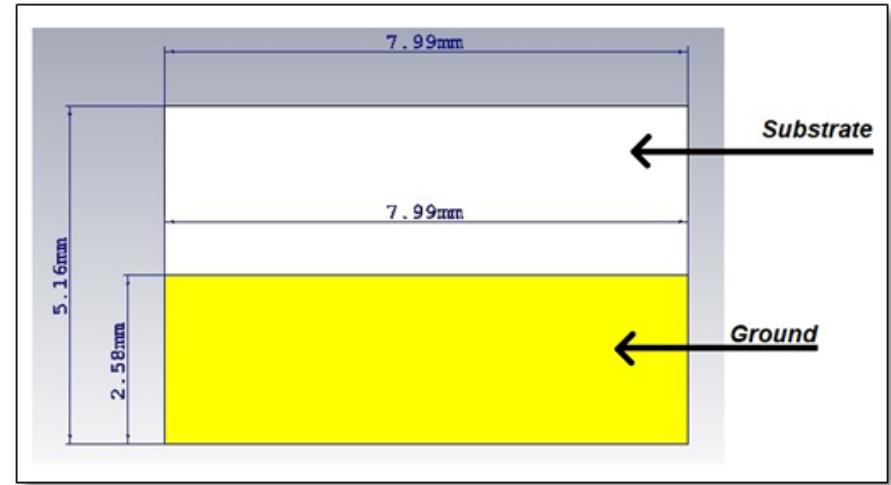

Figure 3: Ground view of Preperm antenna.

This antenna on Preperm substrate can be reproduced using the information in the aforementioned figures as well as Table 2 .

Table 2: Specifications of the Preperm design.

\begin{tabular}{lll} 
S. No & Description & Value \\
1 & Surface area of the Substrate & $5.16 \times 7.99 \mathrm{~mm}^{2}$ \\
2 & Substrate's thickness & $1.75 \mathrm{~mm}$ \\
3 & Surface area of the Patch & $2.73 \times 4.59 \mathrm{~mm}^{2}$ \\
4 & Patch's thickness & $0.1 \mathrm{~mm}$ \\
\hline 5 & Surface area of the Ground & $2.58 \times 7.99 \mathrm{~mm}^{2}$ \\
6 & Ground's thickness & $0.1 \mathrm{~mm}$ \\
7 & Surface area of the Feed & $1.29 \times 0.80 \mathrm{~mm}^{2}$ \\
8 & Feed's thickness & $0.1 \mathrm{~mm}$
\end{tabular}

The results of the above mentioned Preperm antenna has been explained in the results and discussion section of this article.

\section{Mica substrate}

The thickness of the Mica material was $2.15 \mathrm{~mm}$ and its relative permittivity was 6 . The side view, patch view and ground view are exposed in Figures 4, 5 and 6 , respectively. The surface area of the Mica substrate was $11.6 \times 16.02 \mathrm{~mm}^{2}$, while the surface area of the copper patch was $5.5 \times 9.81 \mathrm{~mm}^{2}$. The thickness of the copper patch as well as copper ground was $0.1 \mathrm{~mm}$. The transmission feed line was engaged to energize the structure and its surface area was $1.69 \times 2.89 \mathrm{~mm}^{2}$ as depicted in Figure 5.

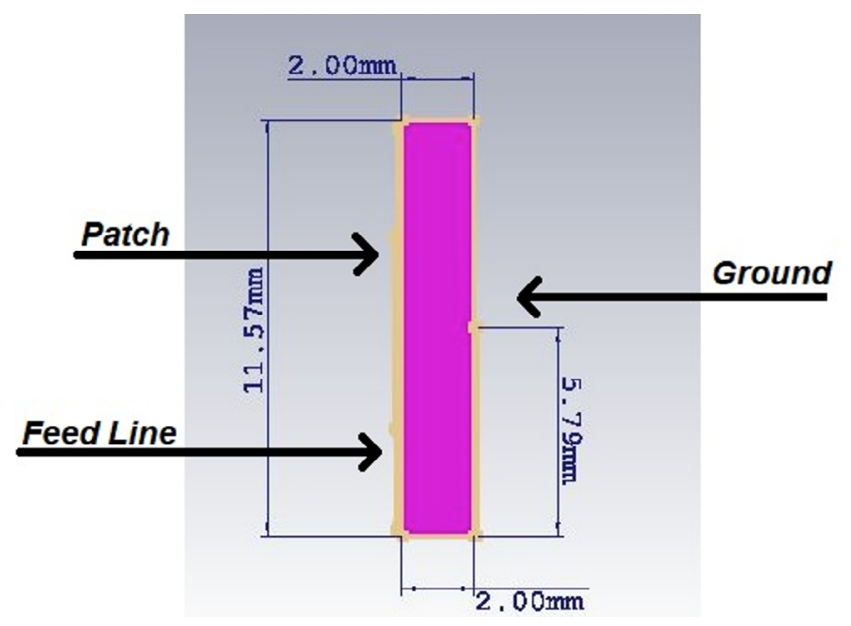

Figure 4: Side view of Mica design.

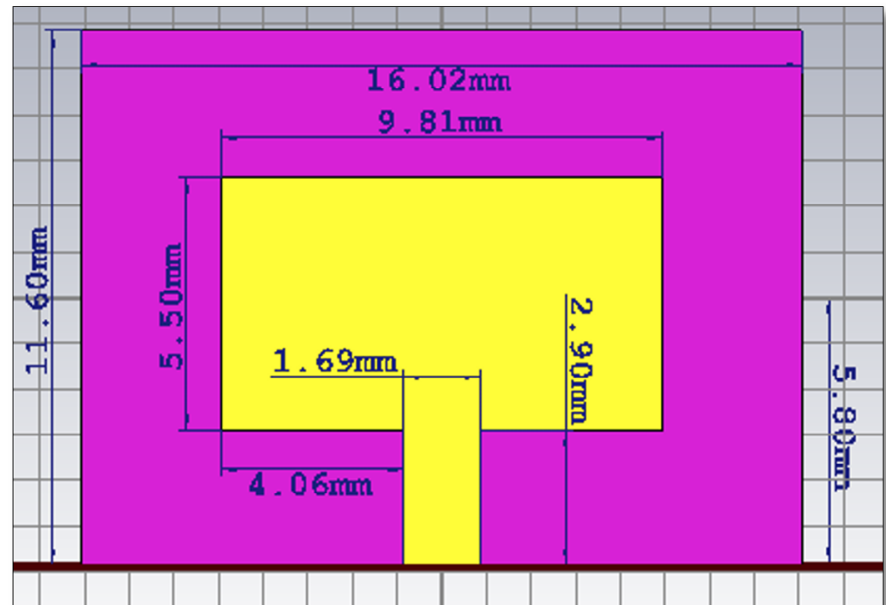

Figure 5: Patch view of Mica antenna.

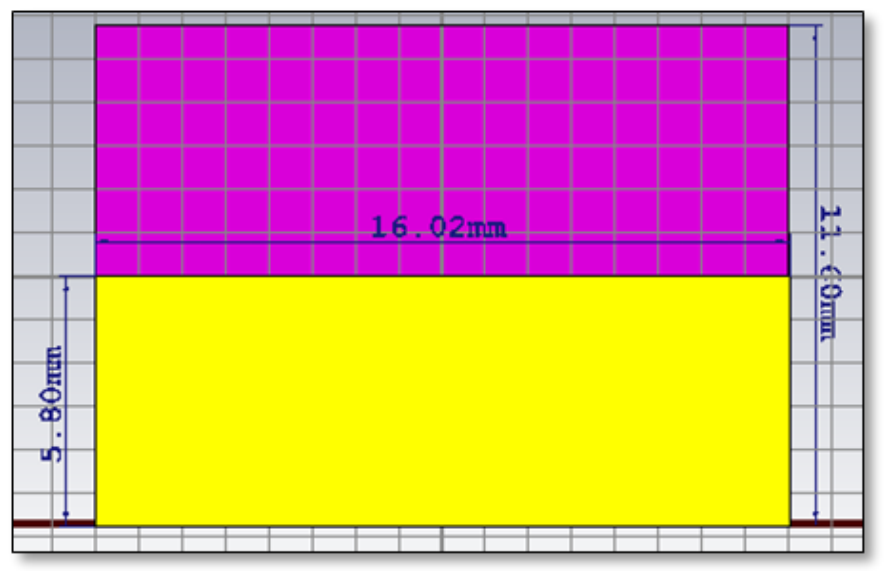

Figure 6: Ground view of Mica antenna.

As evident from Figure 6 the surface area of the copper ground was reduced to make it truncated 
ground structure and its surface area was made equal to $16.02 \times 5.8 \mathrm{~mm}^{2}$. This antenna on Mica substrate can be reproduced using the information in the aforementioned relevant figures as well as Table 3 .

Table 3: Specifications of the Mica design.

$\begin{array}{lll}\text { S. No } & \text { Description } & \text { Value } \\ 1 & \text { Surface area of the substrate } & 11.6 \times 16.02 \mathrm{~mm}^{2} \\ 2 & \text { Substrate's thickness } & 2.15 \mathrm{~mm} \\ 3 & \text { Surface area of the patch } & 5.5 \times 9.81 \mathrm{~mm}^{2} \\ 4 & \text { Patch's thickness } & 0.1 \mathrm{~mm} \\ 5 & \text { Surface area of the ground } & 5.8 \times 16.02 \mathrm{~mm}^{2} \\ 6 & \text { Ground's thickness } & 0.1 \mathrm{~mm} \\ 7 & \text { Surface area of the feed } & 2.9 \times 1.69 \mathrm{~mm}^{2} \\ 8 & \text { Feed's thickness } & 0.1 \mathrm{~mm}\end{array}$

\section{FR-4 substrate}

The thickness of the FR-4 material was $2 \mathrm{~mm}$ and its relative permittivity was 4.3 . The side view, patch view and ground view are exposed in Figures 7, 8 and 9, respectively. The surface area of the FR-4 substrate was $11.51 \times 8.12 \mathrm{~mm}^{2}$, while the surface area of the copper patch was $6.55 \times 3.81 \mathrm{~mm}^{2}$. The thickness of the copper patch as well as copper ground was $0.1 \mathrm{~mm}$. The transmission feed line was engaged to energize the structure and its surface area was $1.21 \times 2.03 \mathrm{~mm}^{2}$ as depicted in Figure 8.

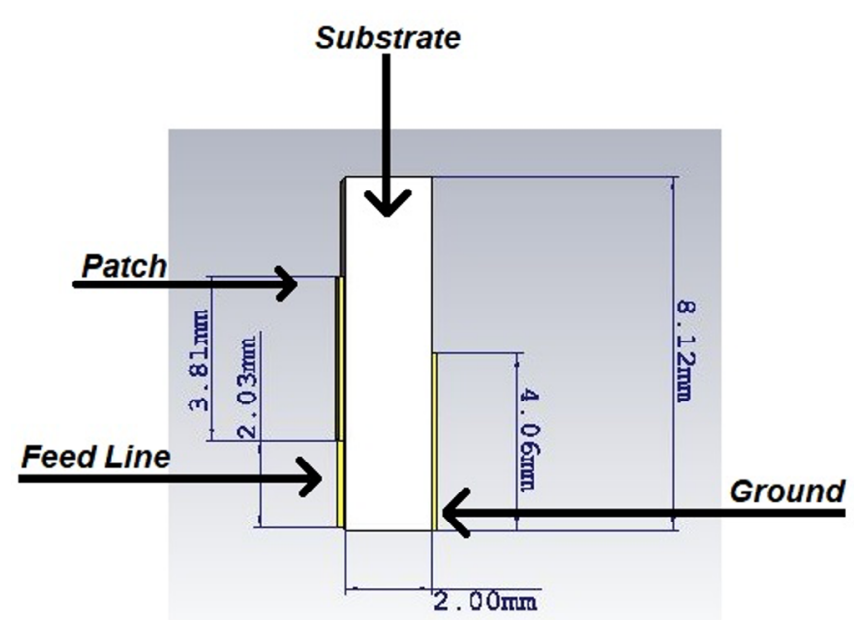

Figure 7: Side view of the FR-4 antenna.

As evident from Figure 9 the surface area of the copper ground was reduced by half to make it truncated ground structure and its surface area was made equal to $11.51 \mathrm{X} 4.06 \mathrm{~mm}^{2}$. The thickness of the copper ground was kept the same but the thickness of the copper patch as well as copper feed line was increased from $0.1 \mathrm{~mm}$ to $0.12 \mathrm{~mm}$. This antenna on FR-4 substrate can be reproduced using the information in the aforementioned relevant figures as well as Table 4 .

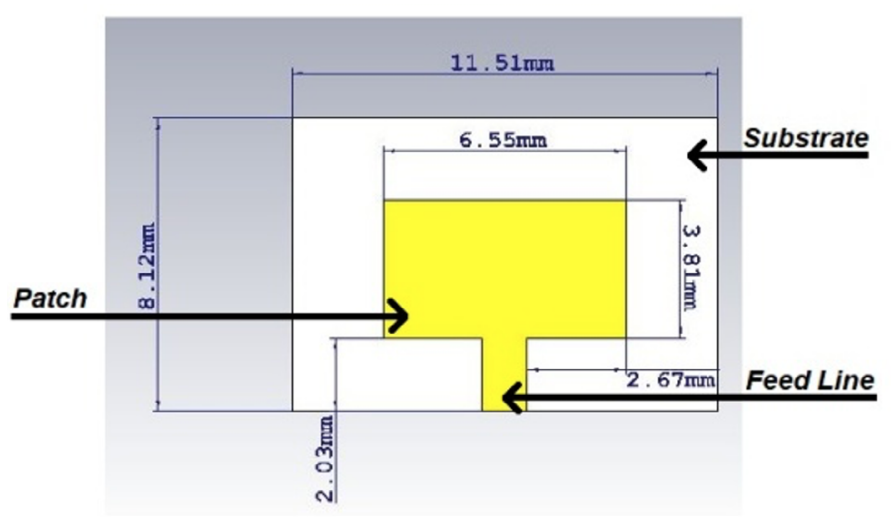

Figure 8: Patch view of the FR-4 antenna.

Table 4: Specifications of the FR-4 design.

\begin{tabular}{lll} 
S. No & Description & Value \\
\hline 1 & Surface area of the substrate & $11.51 \times 8.12 \mathrm{~mm}^{2}$ \\
2 & Substrate's thickness & $2.00 \mathrm{~mm}$ \\
3 & Surface area of the patch & $6.55 \times 3.81 \mathrm{~mm}^{2}$ \\
4 & Patch's thickness & $0.12 \mathrm{~mm}$ \\
\hline 5 & Surface area of the ground & $4.06 \times 11.51 \mathrm{~mm}^{2}$ \\
6 & Ground's thickness & $0.1 \mathrm{~mm}$ \\
7 & Surface area of the feed & $2.03 \times 1.21 \mathrm{~mm}^{2}$ \\
8 & Feed's thickness & $0.12 \mathrm{~mm}$ \\
\hline
\end{tabular}

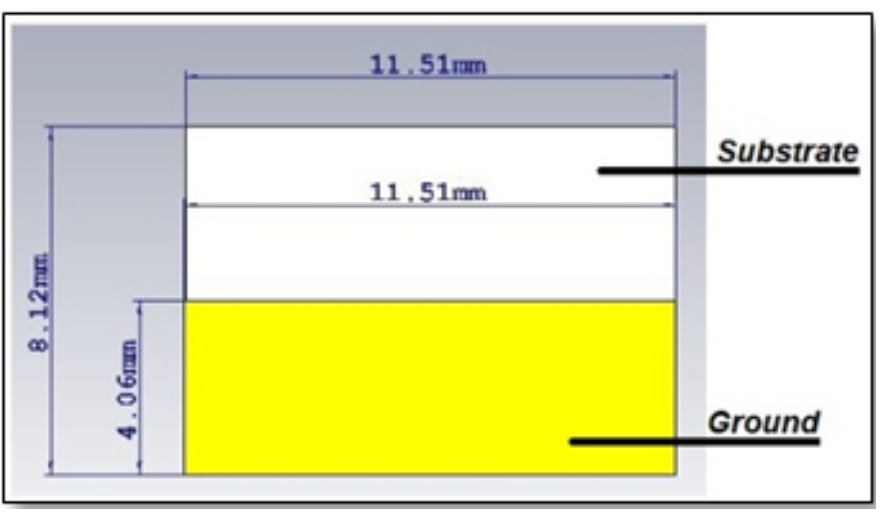

Figure 9: Ground View of the FR-4 Antenna

\section{Results and Discussion}

Various results of all the three designs are analyzed critically in the following sections of this article.

\section{Results of preperm design}

Preperm is a dielectric material and the relative permittivity of the Preperm material used as a substrate of this antenna was 6.8. The antenna on Preperm attained two functional bands as plotted in Figure 10. The first band was from $19.24 \mathrm{GHz}$ June 2020 | Volume 39 | Issue 1 | Page 97 
to $27.15 \mathrm{GHz}$ giving an impedance bandwidth of $7.9 \mathrm{GHz}$. The second band was from $43.66 \mathrm{GHz}$ to $66.61 \mathrm{GHz}$ giving a huge impedance bandwidth of 22.94GHz.

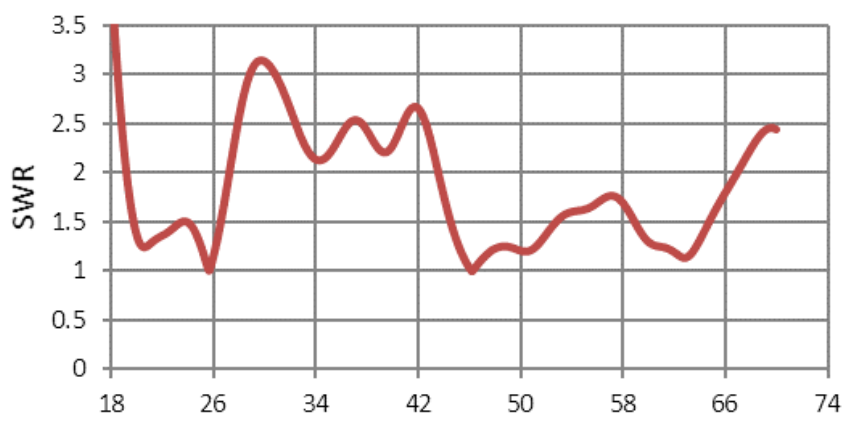

Figure 10: Return loss of Preperm substrate.

The smallest value of the reflection coefficient in the first functional bandwidth was $-42.6 \mathrm{~dB}$ while the smallest value of the reflection coefficient in the $2^{\text {nd }}$ bandwidth was $-48.88 \mathrm{~dB}$ thus demonstrating excellent impedance matching. VSWR was justified in both the bands. Its minimum values in the first and second band were 1.02 and 1.007 which can be confirmed from Figure 11.

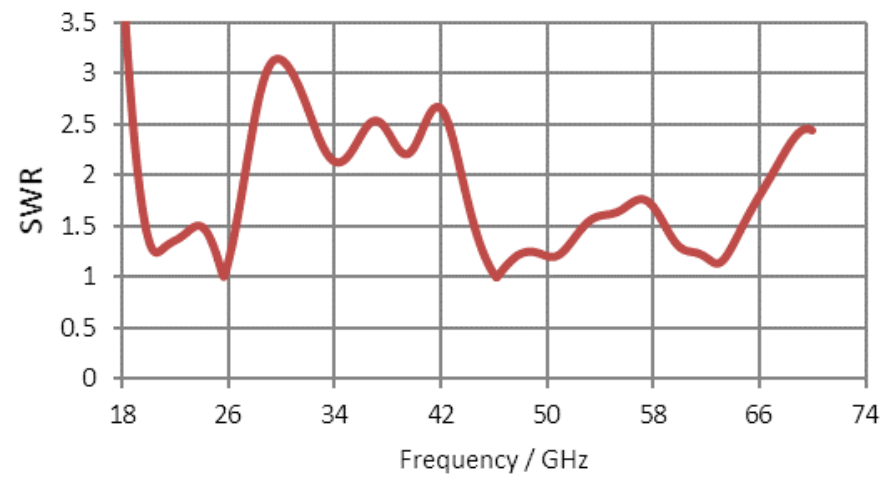

Figure 11: SWR of the PREPERM antenna.

This antenna demonstrated the maximum efficiency in the $2^{\text {nd }}$ band. This maximum value was $77.88 \%$ that occurred at the frequency of $55.5 \mathrm{GHz}$. These values can be confirmed from Figure 12 .

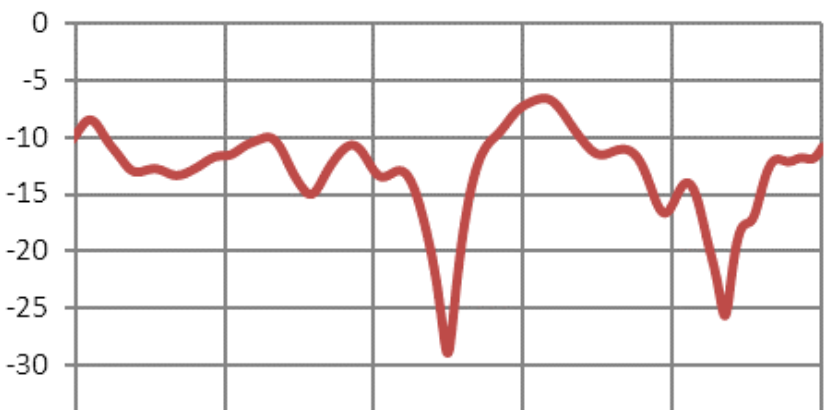

Figure 12: efficiency of PREPERM antenna.
Two values of Gain were recorded at the frequencies of 25.6 and $46.1 \mathrm{GHz}$ in Figure 13 and these values were $3.43 \mathrm{dBi}$ and $4.44 \mathrm{dBi}$, respectively.

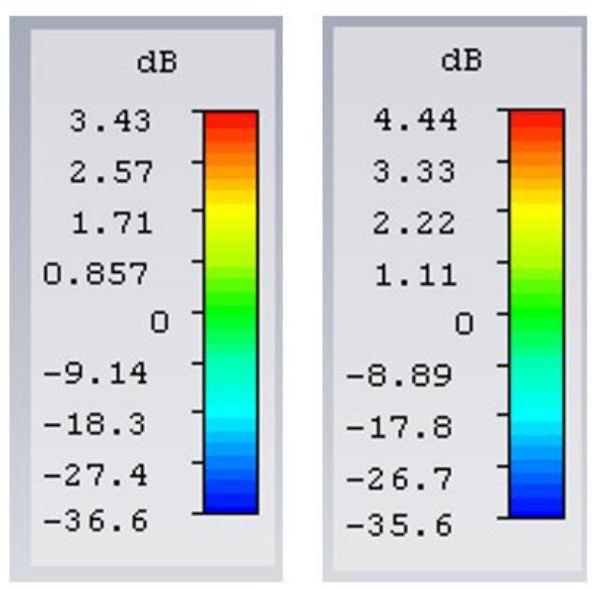

Figure 13: Gain at $25.6 \mathrm{GHz}$ and $46.1 \mathrm{GHz}$.

The important results such as impedance bandwidth, minimum values of reflection coefficient, Minimum values of VSWR, maximum value of efficiency and the Gain values at the center frequencies of the aforementioned design were summarized in Table 5.

Table 5: Summary of results of Preperm antenna.

$\begin{array}{ll}\text { Description } & \text { Values } \\ \text { Impedance Bandwidth of the } 1^{\text {st }} \text { band } & 7.9 \mathrm{GHz} \\ \text { Impedance Bandwidth of the } 2 \text { nd band } & 22.94 \mathrm{GHz} \\ \text { Minimum Value of VSWR of the } 1^{\text {st }} \text { band } & 1.02 \\ \text { Minimum Value of VSWR of the } 2 \text { nd band } & 1.007 \\ \text { Maximum value of the efficiency } & 77.88 \% \\ \text { Gain at the central frequency of the } 1^{\text {st }} \text { bandwidth } & 3.43 \mathrm{dBi} \\ \text { Gain at the central frequency of the } 2^{\text {nd }} \text { bandwidth } 4.44 \mathrm{dBi}\end{array}$

\section{Results of mica design}

Mica is a dielectric material and the relative permittivity of this material, used as a substrate of the antenna, was 6. The antenna on Mica attained two functional bands as plotted in Figure 14. The first band was from $20.04 \mathrm{GHz}$ to $46.06 \mathrm{GHz}$ giving a huge impedance bandwidth of $26.02 \mathrm{GHz}$. The second band was from $51.84 \mathrm{GHz}$ to $68 \mathrm{GHz}$ giving an impedance bandwidth of $16.15 \mathrm{GHz}$.

The smallest value of the reflection coefficient in the first functional band was $-28.87 .6 \mathrm{~dB}$ while the lowest value of the reflection coefficient in the second band was $-25.49 \mathrm{~dB}$ thus demonstrating good impedance matching. VSWR was justified in both the bands. Its minimum values in the first and second band were 
1.07 and 1.11 which can be confirmed from Figure 15.

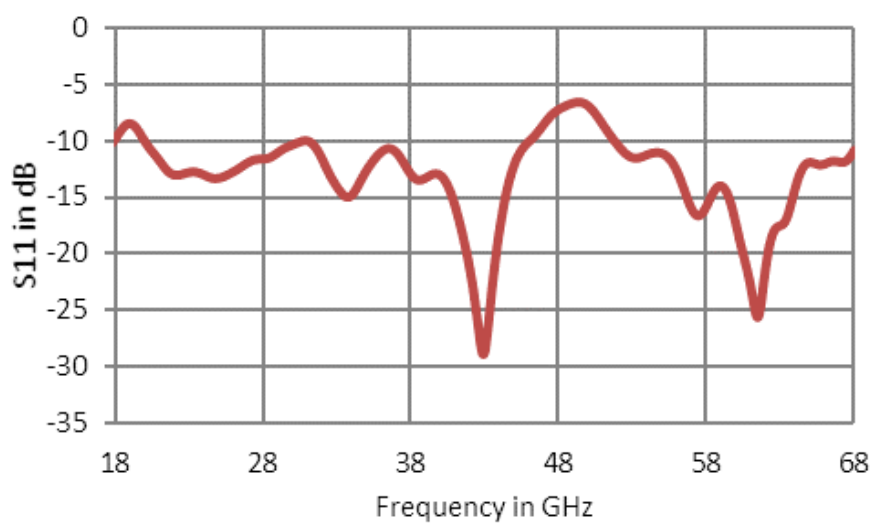

Figure 14: Return loss of mica substrate.

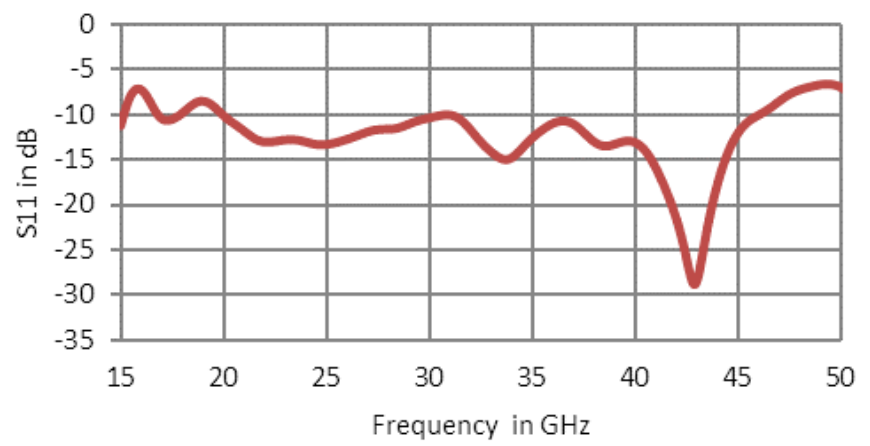

Figure 15: SWR of the MICA antenna.

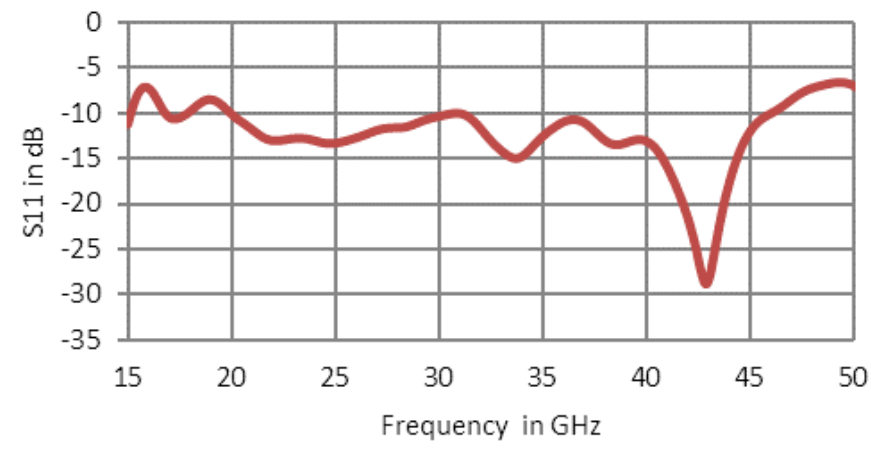

Figure 16: Efficiency of the MICA antenna.

This antenna demonstrated the maximum efficiency in the $1^{\text {st }}$ band. This maximum value was $81.88 \%$ that occurred at the frequency of $29.1 \mathrm{GHz}$. These values can be confirmed from Figure 16 .

Two values of Gain were recorded at the frequencies of $43 \mathrm{GHz}$ and $62 \mathrm{GHz}$ in Figure 17 and these values were recorded as $8.19 \mathrm{dBi}$ and $10.2 \mathrm{dBi}$ respectively.

The important results such as impedance bandwidth, minimum values of reflection coefficient, minimum values of VSWR, maximum value of efficiency and the Gain values at the center frequencies of the June 2020 | Volume 39 | Issue 1 | Page 99 aforementioned design were summarized in Table 6 . The values were compared with the values of the previous design on Preperm Substrate as well.

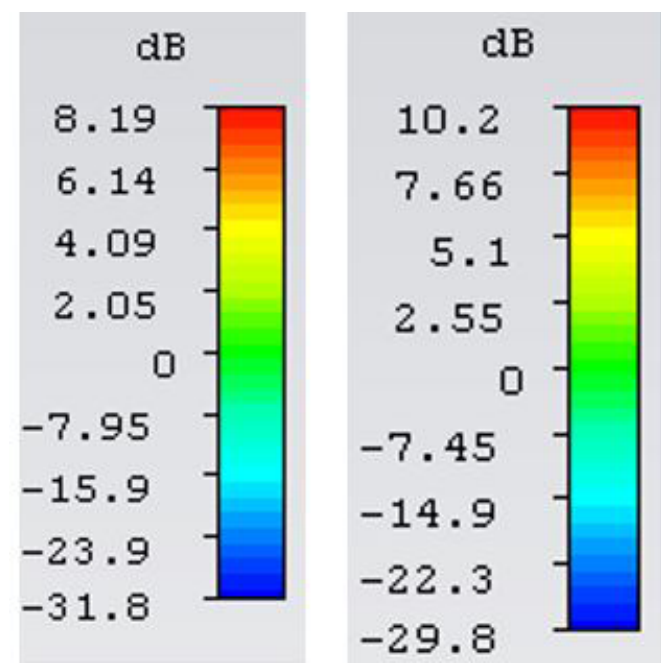

Figure 17: Gain at $43 \mathrm{GHz}$ and $62 \mathrm{GHz}$.

\section{Results of FR-4 design}

FR-4 is a dielectric material and the relative permittivity of this material, used as a substrate of the antenna, was 4.3. The antenna on FR-4 attained a single band as plotted in Figure 18. This single band was from $20.43 \mathrm{GHz}$ to $45.27 \mathrm{GHz}$ giving a huge impedance bandwidth of $24.85 \mathrm{GHz}$.

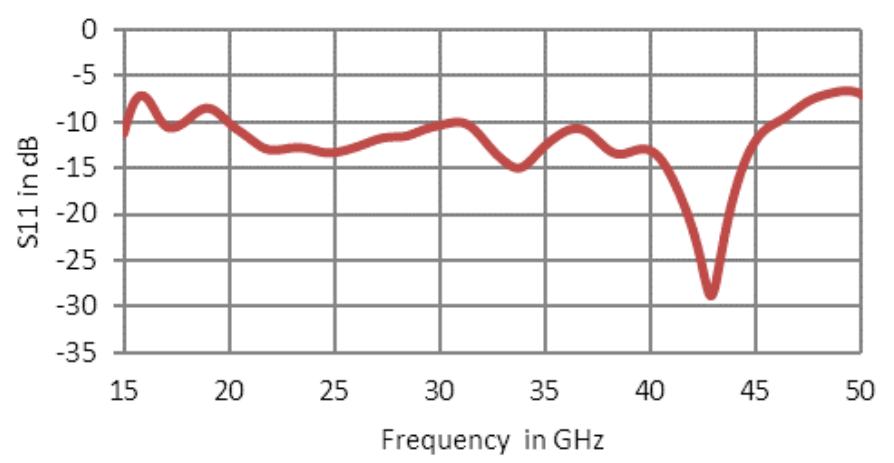

Figure 18: Return loss of FR-4 substrate.

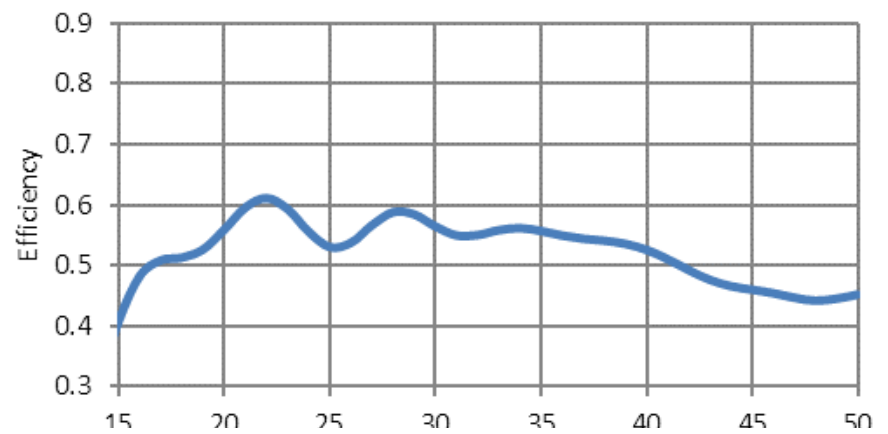

Figure 19: SWR of the FR-4 antenna.

The first lowest value of the reflection coefficient was $-41.27 \mathrm{~dB}$ that occurred at $24.28 \mathrm{GHz}$ while Links Researchers 
the second lowest value of the reflection coefficient was $-34.46 \mathrm{~dB}$ that took place at the frequency of $31.05 \mathrm{GHz}$. VSWR was justified in the mentioned functional band. Two minimum values were recorded as 1.03 and 1.01 which can be confirmed from Figure 19.

This antenna demonstrated the maximum value of efficiency at the frequency of $22 \mathrm{GHz}$. This maximum value was $61.08 \%$ and the minimum value was recorded as $45.27 \%$. These values can be confirmed from Figure 20.

The important results such as impedance bandwidth, minimum values of reflection coefficient, minimum values of VSWR, maximum value of efficiency and the Gain values at the center frequencies of the aforementioned design were summarized in Table
7. The values were compared with the values of the previous design on Mica Substrate as well.

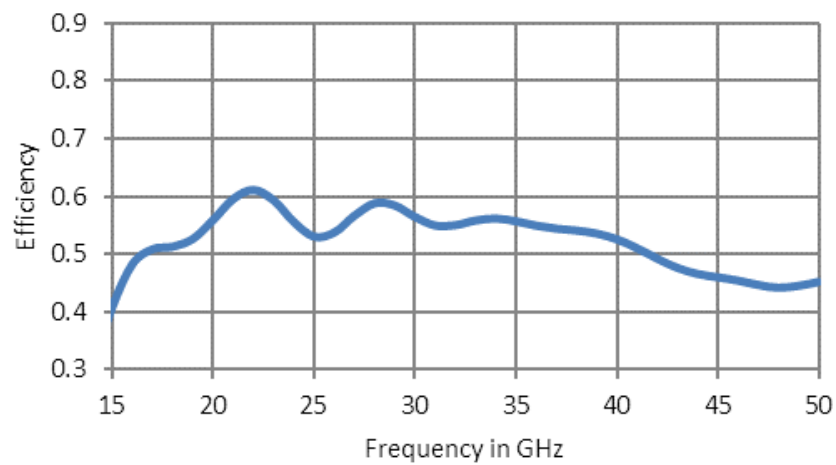

Figure 20: Efficiency of the FR-4 antenna.

Two values of Gain were recorded at the frequencies of $43 \mathrm{GHz}$ and $62 \mathrm{GHz}$ in Figure 21 and these values were recorded as $4.19 \mathrm{dBi}$ and $3.02 \mathrm{dBi}$, respectively.

Table 6: Summary of results of Mica antenna.

$\begin{array}{lll}\text { Description } & \text { Values } & \text { Comparison with Preperm Design } \\ \text { Impedance Bandwidth of the } 1^{\text {st }} \text { band } & 26.06 \mathrm{GHz} & \text { It has attained a larger bandwidth } \\ \text { Impedance Bandwidth of the } 2^{\text {nd }} \text { band } & 16.15 \mathrm{GHz} & \text { It has attained a smaller bandwidth } \\ \text { Minimum Value of VSWR of the } 1^{\text {st }} \text { band } & 1.07 & \text { Almost the same SWR } \\ \text { Minimum Value of VSWR of the } 2^{\text {nd }} \text { band } & 1.1 & \text { This value is greater than the preperm one } \\ \text { Maximum value of the efficiency } & 81.88 \% & \text { It has attained greater efficiency } \\ \text { Gain at a frequency of the } 1^{\text {st }} \text { band } & 8.19 \mathrm{dBi} & \text { It has attained a larger gain } \\ \text { Gain at a frequency of the } 2^{\text {nd }} \text { band } & 10.2 \mathrm{dBi} & \text { It has attained a larger gain }\end{array}$

Table 7: Summary of results of FR-4 antenna.

$\begin{array}{lll}\text { Description } & \text { Values } & \text { Comparison with preperm design } \\ \text { Impedance Bandwidth } & 24.28 \mathrm{GHz} & \text { It has attained a large bandwidth as well } \\ \text { Minimum Value of VSWR } & 1.01 & \text { SWR Value is greater } \\ \text { Maximum value of the efficiency } & 61.08 \% & \text { It has attained greater efficiency } \\ \text { Gain at a frequency of } 31 \mathrm{GHz} & 3.02 \mathrm{dBi} & \text { It has attained smaller gain } \\ \text { Gain at a frequency of } 43 \mathrm{GHz} & 4.2 \mathrm{dBi} & \text { It has attained smaller gain }\end{array}$

Table 8: Comparison of the results of all the three antennas.

\begin{tabular}{llll} 
Description of the characteristics & $\begin{array}{l}\text { Values for preperm } \\
\text { antenna }\end{array}$ & $\begin{array}{l}\text { Values for FR-4 } \\
\text { antenna }\end{array}$ & $\begin{array}{l}\text { Values for Mica } \\
\text { antenna }\end{array}$ \\
$\begin{array}{l}\text { Impedance Bandwidth of the } 1^{\text {st }} \text { band } \\
\text { Impedance Bandwidth of the } 2 \mathrm{nd} \text { band }\end{array}$ & $\begin{array}{l}2.9 \mathrm{GHz} \\
\text { Minimum Value of VSWR of the } 1^{\text {st }} \text { band }\end{array}$ & $\begin{array}{l}24.28 \mathrm{GHz} \\
\text { Single Band }\end{array}$ & $\begin{array}{l}26.06 \mathrm{GHz} \\
16.15 \mathrm{GHz}\end{array}$ \\
Minimum Value of VSWR of the $2^{\text {nd }}$ band & 1.02 & 1.01 & 1.07 \\
Maximum value of the efficiency & 1.007 & & 1.1 \\
Gain at the central frequency of the $1^{\text {st }}$ bandwidth & $77.88 \%$ & $61.08 \%$ & $81.88 \%$ \\
Gain at the central frequency of the $2^{\text {nd }}$ bandwidth & $3.43 \mathrm{dBi}$ & $3.02 \mathrm{dBi}$ at $31 \mathrm{GHz}$ & $8.19 \mathrm{dBi}$ \\
\hline
\end{tabular}

June 2020 | Volume 39 | Issue 1 | Page 100 


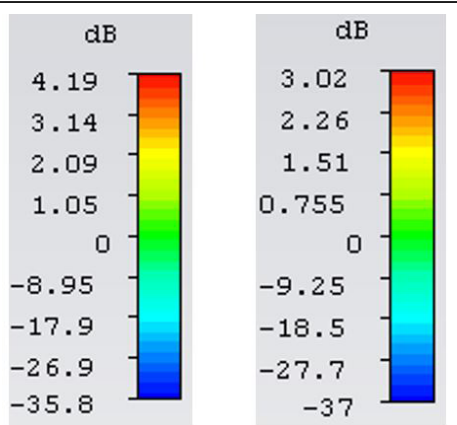

Figure 21: Gain at $43 \mathrm{GHz}$ and $31 \mathrm{GHz}$.

All the three antennas have achieved good results. The comparison of the results of all these antennas is given in Table 8. All these three antennas have achieved good results and can be employed in a wireless communication system having a large bandwidth requirement. The antenna made on the substrate of Mica has attained better results.

This design was compared with some previous designs in Table 9 and the comparison shows that the recommended dual band antenna of this article has attained huge bandwidths of $26 \mathrm{GHz}$ and $16 \mathrm{GHz}$.

Table 9: Comparison with previous designs.

$\begin{array}{ll}\text { (Jajere } \text { et al., 2017) } & 4.5 \mathrm{GHz} \\ \text { (Johary et al., 2018) } & 0.4 \mathrm{GHz} \\ \text { (El-Mashade } \text { et al., 2018) } & 12 \mathrm{GHz} \\ \text { (Sekar } \text { et al., 2018) } & 1.02 \mathrm{GHz}\end{array}$

The recommended antenna of this work $26 \mathrm{GHz}$ and $16 \mathrm{GHz}$

\section{Conclusions and Recommendations}

Three simple rectangular designs on Preperm substrate, Mica substrate and FR-4 substrate were presented in this article. The antenna on FR-4 attained a single band from $20.43 \mathrm{GHz}$ to $45.27 \mathrm{GHz}$ giving a huge impedance bandwidth of $24.85 \mathrm{GHz}$. The maximum value of its efficiency was $61.08 \%$ and the minimum value was $45.27 \%$. The antenna on Preperm attained two functional bands from $19.24 \mathrm{GHz}$ to $27.15 \mathrm{GHz}$ giving an impedance bandwidth of $7.9 \mathrm{GHz}$ and from $43.66 \mathrm{GHz}$ to $66.61 \mathrm{GHz}$ giving a huge impedance bandwidth of $22.94 \mathrm{GHz}$. The maximum value of its total efficiency was $77.88 \%$. Keeping in view their bandwidths and efficiency, it is concluded that all these three designs can be engaged in future for mobile wireless communication. But the antenna on the mica substrate demonstrated better results as compared to the remaining two antennas. It attained huge bandwidths of $26.06 \mathrm{GHz}$ and $16.15 \mathrm{GHz}$ in the $1^{\text {st }}$ and the $2^{\text {nd }}$ band respectively. The total efficiency of the antenna on Mica substrate was $81.88 \%$. The gain at a frequency randomly selected from the $1^{\text {st }}$ bad was $8.19 \mathrm{dBi}$, while the gain at a frequency selected from the $2^{\text {nd }}$ band was $10.2 \mathrm{dBi}$. Surface area of the recommended Mica substrate was $11.6 \times 16.02 \mathrm{~mm}^{2}$. Its thickness was $2.15 \mathrm{~mm}$. Surface area of the Patch was $5.5 \times 9.81 \mathrm{~mm}^{2}$. Surface area of the Ground was $5.8 \times 16.02 \mathrm{~mm}^{2}$. Surface area of the feed was $2.9 \times 1.69$ $\mathrm{mm}^{2}$. The thickness of the copper used in the ground as well as patch was $0.1 \mathrm{~mm}$. Based on the results attained from the simulator, it is established that the antenna on the Mica substrate will be the best antenna for future wireless mobile applications as compared to the remaining two antennas.

\section{Novelty Statement}

Three simple rectangular patch structures were designed on three different insulated substrates including FR-4, Mica and Preperm. The parametric optimization of these antennas attained huge dual bandwidths of $26.06 \mathrm{GHz}$ and $16.16 \mathrm{GHz}$ respectively. It attained an efficiency of $81.88 \%$ and a maximum gain of $8.19 \mathrm{dBi}$ that has never been attained with such a simple design.

\section{Author's Contribution}

All the authors designed the structures using CST Simulation software and carried out the parametric optimization of all the three designs for attaining better results at higher frequency bands for future wireless mobile applications.

\section{Conflict of interest}

The authors have declared no conflict of interest.

\section{References}

Ahmad, G. and M.I. Babar. 2019. An efficient patch antenna with improved bandwidth for future applications.J. Eng. Appl. Sci., 38(1): 2019.

Ahmad, G., M.I. Babar, M. Irfan and R. Edwards. 2018. Analysis of patch antenna with two different substrate materials for $\mathrm{Ku}-\mathrm{Band}$ communications. Sindh Univ. Res. J., (Sci. Ser.). 50(2): 303-310.

Ahmad, G., M.I. Babar, M. Irfan, M. Ashraf, T. Jan and S.W. Shah. 2018. Bandwidth enhancement of patch antenna through various techniques 
for Ku-Band application. Proc. Pak. Acad. Sci. Phys. Comput. Sci., 55(1): 109-116.

Amba, S. and P. Nandita. 2017. Analysis of different substrate material and frequency on microstrip patch antenna. Int. J. Electron. Elect. Comput. Syst., 6(2): 73-78.

El-Mashade, M.B. and E.A. Hegazy. 2018. Design and analysis of $28 \mathrm{GHz}$ rectangular microstrip patch array antenna. Wseas Transact. Commun., 17(1): 1-9.

Gurpreet, K. and G. Sonia. 2016. To study the effect of substrate material for microstrip antenna. Int. J. Eng. Trends Technol., 36(9). https://doi. org/10.14445/22315381/IJETT-V36P289

Israa, H.A. and K.A. Riyadh. 2018. The effects evaluation of various dielectric substrate of square patch antenna on SAR level for human head. J. Eng. Appl. Sci., 13(9): 2761-2766.

Jajere, A.M., 2017. Millimeter wave patch antenna design antenna for future $5 \mathrm{G}$ applications. Int. J. Eng. Res. Technol., 6(2): 289-291. https:// doi.org/10.17577/IJERTV6IS020156

Johari, S., M.A. Jalil, S.I. Ibrahim, M.M. Mohammad and N. Hassan. 2018. 28GHz microstrip patch antennas for future 5G.J. Eng.
Sci. Res., 2(4): 1-6.

Khan, A. and N. Rajesh. 2012. Analysis of five different dielectric substrates on microstrip patch antenna. Int. J. Comput. Appl., 55(14): 0975-8887. https://doi.org/10.5120/88262905

Lakshmu, N.M., R.B. Rama and R.C. Dharma. 2017. Compact rectangular microstrip patch antenna with defected ground structure (DGS) of swastik shape for LTE applications. Int. J. Appl. Eng. Res., 12(20): 10063-10067.

Mohamed, B.E., 2017. Design and analysis of rectangular microstrip patch array antenna for fifth generation of mobile technology. SciFed J. Telecommun., 1(1): 1-9.

Nor, N.M., M.H. Jamaluddin, M.R. Kamarudin and M. Khalily. 2016. Rectangular dielectric resonator antenna array for $28 \mathrm{GHz}$ applications. Prog. Electromagn. Res. C., 63: 53-61. https:// doi.org/10.2528/PIERC16022902

Sekar, C. and M.T. Guneser. 2018. A single band antenna design for future millimeter wave wireless communication at $38 \mathrm{GHz}$. Eur. J. Eng. Form. Sci., 3(1): 35-39. 